\title{
Commentary: Thiamine Deficiency in Tropical Pediatrics: New Insights into a Neglected but Vital Metabolic Challenge
}

\author{
Heitor Pons Leite ${ }^{1 *}$, Lúcio Flávio Peixoto de Lima ${ }^{2}$ and Tulio Konstantyner ${ }^{1}$ \\ ${ }^{1}$ Pediatrics, Discipline of Nutrition and Metabolism, Federal University of São Paulo, São Paulo, Brazil, \\ ${ }^{2}$ Pediatrics, Pediatric Intensive Care Unit, Federal University of São Paulo, São Paulo, Brazil
}

Keywords: thiamine deficiency, refeeding syndrome, malnutrition, beriberi, intensive care units, pediatric

\section{A commentary on}

Thiamine deficiency in tropical pediatrics: new insights into a neglected but vital metabolic challenge

by Hiffler L, Rakotoambinina B, Lafferty N, Martinez Garcia D. Front Nutr (2016) 3:16. doi:10.3389/ fnut.2016.00016

OPEN ACCESS

Edited by:

Kazim Sahin,

Firat University, Turkey

Reviewed by:

N. Charles Harata,

University of Iowa, USA

*Correspondence:

Heitor Pons Leite

heitorpons@gmail.com

Specialty section:

This article was submitted to

Clinical Nutrition,

a section of the journal

Frontiers in Nutrition

Received: 25 October 2016 Accepted: 19 December 2016

Published: 16 January 2017

Citation:

Leite HP, Peixoto de Lima LF and Konstantyner T (2017) Commentary:

Thiamine Deficiency in Tropical

Pediatrics: New Insights into a

Neglected but Vital Metabolic

Challenge.

Front. Nutr. 3:58.

doi: 10.3389/fnut.2016.00058
Although there have been health-care improvements in recent decades, it is a fact that nutritional deficiencies persist in children worldwide $(1,2)$. One of these is thiamine deficiency (TD). In a comprehensive review, Hiffler et al. (3) have addressed two relevant questions for the management of TD in resource-poor settings that are as follows: (1) the early diagnosis of TD depends on clinical awareness and (2) the need for early thiamine supplementation during the refeeding of malnourished children. The review adds significant insight into the problem and gives the opportunity to discuss diagnosis, management, and the rationale for including thiamine in children nutritional support.

Thiamine deficiency is less common than in the past but still occurs endemically as beriberi in children and nursing mothers living in rural areas of Southeast Asia (4-9) and as outbreaks in different parts of the world (10-12). The clinical spectrum of TD may vary according to the clinical setting, age, and individual susceptibility (13). Infantile beriberi typically presents as heart failure, dysphonia, and increased irritability $(5,14,15)$. However, the classical diagnostic criteria for infantile beriberi may be non-specific for diagnosis of TD in endemic regions, where the disease may often be clinically unapparent (5). As early symptoms are non-specific, biochemical analysis is unavailable in resource-limited settings, and food intake records are usually inaccurate for a timely diagnosis of deficiency, it is not known just how widespread subclinical TD is.

An issue not addressed in this review is that the clinical expression of a micronutrient deficiency is a result of a progressive process whose duration is variable, dependent on reserves, consumption, and food intake. In an initial phase, there is a depletion of the reserves followed by decreased intracellular concentration. If inadequate intake persists, metabolic changes occur, followed by non-specific functional defects (subclinical deficiency). The end result of this process will be a clinical deficiency state and ultimately death (16). Given its very limited body stores, the time taken to pass through these different phases are shorter for thiamine (13). This can be particularly worrying in the case of malnourished and critically ill patients.

A comment should be made on the laboratory diagnosis of TD. Hiffler et al. refer to the limitations of serum or whole blood thiamine as a marker of thiamine status during the systemic inflammatory response. This is true regarding serum or plasma thiamine (which is transiently reduced following an inflammatory insult), but not for whole blood thiamine. The erythrocytes contain 
approximately $80 \%$ of the total thiamine in whole blood, predominantly thiamine diphosphate (TDP). TDP concentration in erythrocytes is a good indicator of body stores and correlates strongly with that in whole blood (17). Both whole blood and red cell TDP concentrations, as assessed by high-performance liquid chromatography, are accurate indicators of thiamine status. In addition, direct measurements of thiamine stores are better than functional assays (i.e., erythrocyte transketolase activity) because the latter can be influenced by factors other than vitamin deficiency $(17,18)$.

The risk of TD in the ICU setting is another concern, especially in patients in whom parenteral nutrition or full-rate enteral tube feeding is delayed because of fluid restriction, hemodynamic instability, or gastrointestinal intolerance. Thiamine supplementation is recommended for these patients and those with heart failure, receiving diuretics, or renal replacement therapy $(19,20)$. The use of thiamine as a potential metabolic resuscitator has been tested in septic shock patients. In a randomized controlled trial by Donnino et al., thiamine administration did not improve lactate levels or clinical outcomes in adults with septic shock the overall group. However, it is noteworthy that in those with baseline TD, patients in the thiamine-supplemented group had lower serum lactate at $24 \mathrm{~h}$ and in-hospital mortality (21). Further studies are necessary to determine which groups of patients are expected to benefit from this intervention.

Apart from being associated with increased risk of illnessrelated mortality in sick children in poor areas (22), TD may cause long-term sequelae, and not only in developing countries. In Israel, two deaths from cardiomyopathy, neurological deficits, and developmental delay were documented in infants exclusively fed soy formula that did not contain thiamine (23).

Thiamine supplementation at initiation of severe malnutrition treatment is not the current practice in pediatric hospitals

\section{REFERENCES}

1. GBD 2015 SDG Collaborators. Measuring the health-related Sustainable Development Goals in 188 countries: a baseline analysis from the Global Burden of Disease Study 2015. Lancet (2016) 388:1813-50. doi:10.1016/ S0140-6736(16)31467-2

2. Bhutta ZA, Salam RA. Global nutrition epidemiology and trends. Ann Nutr Metab (2012) 61(Suppl 1):19-27. doi:10.1159/000345167

3. Hiffler L, Rakotoambinina B, Lafferty N, Martinez Garcia D. Thiamine deficiency in tropical pediatrics: new insights into a neglected but vital metabolic challenge. Front Nutr (2016) 3:16. doi:10.3389/fnut.2016. 00016

4. Khounnorath S, Chamberlain K, Taylor AM, Soukaloun D, Mayxay $\mathrm{M}$, Lee SJ, et al. Clinically unapparent infantile thiamin deficiency in Vientiane, Laos. PLoS Negl Trop Dis (2011) 5(2):e969. doi:10.1371/journal. pntd.0000969

5. Coats D, Shelton-Dodge K, Ou K, Khun V, Seab S, Sok K, et al. Thiamine deficiency in Cambodian infants with and without beriberi. J Pediatr (2012) 161(5):843-7. doi:10.1016/j.jpeds.2012.05.006

6. Coats D, Frank EL, Reid JM, Ou K, Chea M, Khin M, et al. Thiamine pharmacokinetics in Cambodian mothers and their breastfed infants. Am J Clin Nutr (2013) 98:839-44. doi:10.3945/ajcn.113.062737

7. Barennes H, Sengkhamyong K, René JP, Phimmasane M. Beriberi (thiamine deficiency) and high infant mortality in northern Laos. PLoS Negl Trop Dis (2015) 9(3):e0003581. doi:10.1371/journal.pntd.0003581

8. Whitfield KC, Karakochuk CD, Liu Y, Mccann A, Talukder A, Kroeun H, et al. Poor thiamin and riboflavin status is common among women of childbearing or ambulatory settings. Furthermore, thiamine content of milk formulas given to malnourished children is not enough to satisfy their estimated requirements during the refeeding, as depicted in Table 1 of the review (3). Since children with severe malnutrition may have low or borderline thiamine stores, they are prone to develop TD during refeeding without thiamine supplementation. Given that beriberi clinical features are non-specific for TD diagnosis, a policy recommendation for empirical therapy with thiamine would be justified for sick children living in endemic areas, emergency-affected populations, and those patients who are critically ill and at risk of TD $(4,24-26)$. Laboratory confirmation is not required to treat at-risk patients in low resource settings. No tolerable upper intake level has been set for thiamine (27). In severe deficiency states, oral and intravenous administration of doses far above the daily recommended intake for healthy people is considered safe.

To date, TD continues to be under-recognized in malnourished children. The review by Hiffler et al. calls to attention the need for thiamine supplementation in critically ill patients and reminds us that TD must be regarded as a public health problem in poor areas and humanitarian fields. Clinical awareness and early thiamine supplementation are the safest approaches to prevent deficiencyrelated complications and mortality.

\section{AUTHOR CONTRIBUTIONS}

HL conceived, wrote, and revised the manuscript. TK and LL contributed to the writing and critically revised the manuscript. All the authors gave their final approval.

\section{FUNDING}

This work received no specific financial support.

age in rural and urban Cambodia. J Nutr (2015) 145:628-33. doi:10.3945/ jn.114.203604

9. Ortega RM, Martínez RM, Andrés P, Marín-Arias L, López-Sobaler AM. Thiamin status during the third trimester of pregnancy and its influence on thiamin concentrations in transition and mature breast milk. Br J Nutr (2004) 92:129-35. doi:10.1079/BJN20041153

10. Thurnham DI, Cathcart AE, Livingstone MB. A retrospective investigation of thiamin and energy intakes following an outbreak of beriberi in The Gambia. Nutrients (2011) 3:135-51. doi:10.3390/nu3010135

11. Watson JT, El Bushra H, Lebo EJ, Bwire G, Kiyengo J, Omballa V, et al. Outbreak of beriberi among African Union troops in Mogadishu, Somalia. PLoS One (2011) 6(12):e28345. doi:10.1371/journal.pone.0028345

12. Napon C, Somé P, Maiga Y, Kaboré J. Polyneuropathies of pregnancy and the postpartum period in Burkina Faso. Méd Santé Trop (2012) 22(2):153-6. doi:10.1684/mst.2012.0061

13. Sechi G, Serra A. Wernicke's encephalopathy: new clinical settings and recent. Lancet Neurol (2007) 6:442-55. doi:10.1016/S1474-4422(07)70104-7

14. Qureshi AU, Sami A, Altaf U, Ahmad K, Iqbal J, Wani NA, et al. Thiamine responsive acute life threatening metabolic acidosis in exclusively breast-fed infants. Nutrition (2016) 32(2):213-6. doi:10.1016/j.nut.2015.08.007

15. World Health Organization, United Nations High Commissioner for Refugees. In: World Health Organization, editor. Thiamine Deficiency and Its Prevention and Control in Major Emergencies. WHO/NHD/99.13. 52 p. Available from: http://www.who.int/nutrition/publications/emergencies/ WHO_NHD_99.13/en/

16. Shenkin A. The key role of micronutrients. Clin Nutr (2006) 25(1):1-13. doi:10.1016/j.clnu.2005.11.006 
17. Talwar D, Davidson H, Cooney J, St JO'Reilly D. Vitamin B(1) status assessed by direct measurement of thiamin pyrophosphate in erythrocytes or whole blood by HPLC: comparison with erythrocyte transketolase activation assay. Clin Chem (2000) 46(5):704-10.

18. Lu J, Frank EL. Rapid HPLC measurement of thiamine and its phosphate esters in whole blood. Clin Chem (2008) 54(5):901-6. doi:10.1373/ clinchem.2007.099077

19. Lima L, Leite H, Taddei J. Low blood thiamine concentrations in children upon admission to the intensive care unit: risk factors and prognostic significance. Am J Clin Nutr (2011) 93:57-61. doi:10.3945/ajcn.2009.29078

20. Leite HP, Lima LF. Thiamine (vitamin B1) deficiency in intensive care: physiology, risk factors, diagnosis, and treatment. In: Rajendram R, Preedy VR, Patel VB, editors. Diet and Nutrition in Critical Care. New York: Springer Science+Business Media (2014). p. 1-16.

21. Donnino MW, Andersen LW, Chase M, Berg KM, Tidswell M, Giberson T, et al. Randomized, double-blind, placebo-controlled trial of thiamine as a metabolic resuscitator in septic shock: a pilot study. Crit Care Med (2016) 44(2):360-7. doi:10.1097/CCM.0000000000001572

22. Luxemburger C, White N, ter Kuile F, Singh HM, Allier-Frachon I, Ohn $\mathrm{M}$, et al. Beri-beri: the major cause of infant mortality in Karen refugees. Trans R Soc Trop Med Hyg (2003) 97:251-5. doi:10.1016/S0035-9203(03) 90134-9

23. Fattal-Valevski A, Kesler A, Sela BA, Nitzan-Kaluski D, Rotstein M, Mesterman $\mathrm{R}$, et al. Outbreak of life-threatening thiamine deficiency in infants in Israel caused by a defective soy-based formula. Pediatrics (2005) 115(2):e233-8. doi:10.1542/peds.2004-1255

24. Bowman BA, Pfeiffer CM, Barfield WD. HHS public access. Am J Clin Nutr (2013) 98(3):635-6. doi:10.3945/ajcn.113.069419

25. Porter SG, Coats D, Fischer PR, Ou K, Frank EL, Sreang P, et al. Thiamine deficiency and cardiac dysfunction in Cambodian infants. JPediatr (2014) 164(6):1456-61. doi:10.1016/j.jpeds.2014.01.049

26. Mehanna HM, Moledina J, Travis J. Refeeding syndrome: what it is, and how to prevent and treat it. BMJ (2008) 336(7659):1495-8. doi:10.1136/ bmj.a301

27. Otten JJ, Hellwig JP, Meyers LD. Dietary Reference Intakes. Nutrition in Pediatrics. National Academies Press (2006). 1344 p. Available from: http://www.nap.edu/catalog/11537/dietary-reference-intakes-theessential-guide-to-nutrient-requirements

Conflict of Interest Statement: The authors declare that the research was conducted in the absence of any commercial or financial relationships that could be construed as a potential conflict of interest.

Copyright (c) 2017 Leite, Peixoto de Lima and Konstantyner. This is an open-access article distributed under the terms of the Creative Commons Attribution License (CC BY). The use, distribution or reproduction in other forums is permitted, provided the original author(s) or licensor are credited and that the original publication in this journal is cited, in accordance with accepted academic practice. No use, distribution or reproduction is permitted which does not comply with these terms. 